\title{
Representación, visibilización y resistencia de las "otras" víctimas del conflicto armado en Colombia
}

\author{
Andrés Aluma-Cazorla / Connecticut State College-Norwalk
}

Desde principios del presente siglo, existe en Colombia un marcado interés de una gran parte de la población por lograr la anhelada reconciliación, primero, a raíz de la muy controvertida desmovilización de los grupos paramilitares en 2006 y, segundo, después del proceso que culminó en 2016 con la firma de los acuerdos de paz entre el gobierno y las Fuerzas Armadas Revolucionaria de Colombia (FARC), el grupo insurgente más importante del país. Como parte del proceso de paz, el gobierno nacional establece la creación de un Centro Nacional de Memoria Histórica, el cual tiene como objeto reunir y recuperar todo el material documental relativo a las violaciones de los derechos humanos con la misión de:

contribuir a la realización de la reparación integral y el derecho a la verdad del que son titulares las víctimas y la sociedad en su conjunto así como al deber de memoria del Estado con ocasión de las violaciones ocurridas en el marco del conflicto armado colombiano (CNMH 2014).

Esta iniciativa es la primera del siglo XXI que se recordará, entre otros aspectos, por tener un enfoque diferenciado de género, no solo de mujer, sino del tema LGBT, como se registra en sus informes Aniquilar la diferencia: lesbianas, gays, bisexuales y transgeneristas en el marco del conflicto armado colombiano (2015); Un carnaval de resistencia: Memorias del reinado trans del río Tuluní (2018); y Ser marica en medio del conflicto armado: Memorias de sectores LGBT en el Magdalena Medio (2019).

En este artículo, exploro una muestra de estrategias de visibilización y representación en la literatura y las artes audiovisuales de algunas de las víctimas percibidas como "anormales" (lesbianas, gays, bisexuales y transgeneristas) por estar fuera de la norma social del género y de la sexualidad, en el marco del conflicto armado colombiano. Analizo, desde la producción cultural y artística, las expresiones de resistencias a la heteronormatividad en dos novelas y un documental. Asimismo, pongo de manifiesto su posible relevancia histórica en los futuros escenarios del postconflicto. Estas obras las constituyen las novelas Lady masacre (2013) de Mario Mendoza, Un mundo huérfano (2016) de Giuseppe Caputo, y el documental Señorita María, la falda de la montaña (2017), dirigido por Rubén Mendoza y coproducido por Amanda Sarmiento y Mendoza.
Para hacer referencia a esta resistencia y este distanciamiento de la norma heterocentrada, tomo como marco de referencia a la teoría queer, cuya noción implica un ejercicio a través del cual el sujeto considerado abyecto y marginalizado se reapropia del término por medio del cual era degradado y lo transforma para empoderarse y oponerse, así, a dicha degradación y marginalización. Judith Butler afirma en Bodies That Matter que el término queer solía significar degradación, pues éste se utilizaba como un estigma paralizante, como la interpelación mundana de una sexualidad patologizada. Este término, sin embargo, experimentó una resignificación afirmativa, a partir de la cual adquirió una serie de significaciones también afirmativas $(1993,313)$ que pongo en evidencia en los trabajos de los artistas que analizo: un ejercicio de empoderamiento a través de la representación de sujetos abyectos y marginalizados que se reapropian del término con que se los degrada para apoderarse y oponerse a dicha degradación.

Dentro de las características principales de lo queer se asume la de "torcer." Como sostiene Eve Kosofsky Sedgwick, "the word 'queer' itself means across - it comes from the Indo-European root -twerkw, which also yields the German quer (transverse), Latin torquere (to twist), English athwart" (1993, xii)." Lo queer, entonces, podría cruzar las narrativas y discursos, las formas y estilos de los que están compuestos para torcerlos y desviarlos, transformándolos, desde el sitio de la sexualidad y el género no normativo. María Amelia Viteri, José Fernando Serrano y Salvador Vidal Ortiz (2011) nos recuerdan cómo, tras el surgimiento del término queer, éste se traduce en América Latina y España como "raro," "maricón," "torcido," "desviado" y a su vez "redefine identidades sexuales y de género, y confronta tendencias asimilacionistas y normalizadoras del género y la sexualidad" $(2011,48)$. Es justamente esta potencialidad de lo queer la que permite sostener que los trabajos de los artistas que analiza este trabajo tuercen, desvían y transforman los distintos lenguajes a los cuales se enfrentan, con el fin de tomar distancia de la norma heterosexual y hacer visibles orientaciones sexuales o identidades de género no normativas, como se verá en la exposición de cada uno de ellos. 


\section{Un mundo huérfano}

Si bien es cierto que varios escritores colombianos han comenzado a narrar con la presencia de un protagonista homosexual-Albalucía Ángel con Misiá señora (1982), Fernando Molano con su novela Un beso de Dick (1992), Fernando Vallejo con La virgen de los sicarios (1994), Jaime Manrique Ardila con Luna latina en Manhattan (2003), Efraím Medina con Érase una vez el amor pero tuve que matarlo (2003), Alonso Sánchez Baute con Al diablo la maldita primavera (2003) - , no son muchas las novelas que hablen de las víctimas LGBT en Colombia. ${ }^{1}$ Quizás la más reconocida recientemente y que ha recibido críticas muy positivas por parte del público especializado es la obra Un mundo huérfano de Giuseppe Caputo, publicada en Colombia a mediados del 2016.

La novela está compuesta por cientos de viñetas en donde se narran las noches que pasa un joven con su padre, los dos anónimos, en una casa miserable de un barrio marginado y oscuro de una ciudad también sin nombre y que está ubicada frente al mar (suponemos que en el Caribe). El uso de las viñetas le da a la narración un ritmo de lectura rápido, a veces sin pausas, en el que se describe a padre e hijo pasando por un momento de mucha dificultad económica en un mundo de carencias donde la comida es poca, no hay trabajo estable, y el dinero y la luz escasean por igual. La atemporalidad en la que estos personajes viven (pronunciada por el hecho de que todas las escenas de la novela transcurren de noche) es contrastada con varias escenas de fiesta gay y de encuentros sexuales que hacen parte de la vida del hijo. En la novela, las zonas ricas descritas por el protagonista están muy iluminadas, mientras la historia transcurre en medio de la oscuridad característica de los barrios más marginados. Sin embargo, los episodios en los que el narrador disfruta de la vida nocturna en la discoteca gay son narrados con euforia, destacando la luminosidad del antro:

En medio del aire, las jaulas empiezan a abrirse. "Esto es hermoso", dice el hombre. "Hermoso". Su emoción me conmueve. Las luces van, vuelven. Todo es luz. Pum, pum, ¡chas! Pum, pum, ¡chas! (Caputo 2016, cap. VI, doc. 2428).

La luz representa el poder, y la ausencia de ésta, la desposesión. De hecho, en Un mundo huérfano la noche resulta ser, en últimas, la encarnación del sentimiento de abandono. Los personajes se van quedando huérfanos de la sociedad y de la solvencia económica, e incluso hasta de ellos mismos: el hijo resulta convertido en padre de su padre, al sufrir este último un derrame cerebral.

Al tiempo que el hijo intenta alimentar a su padre y sacarlo de la inmovilidad a la que él se abandona, vive la otra cara de la noche: frecuenta lugares en los que los hombres caminan, mirando qué otros hombres responden a su mirada; visita saunas donde los encuentros sexuales son tan variados y numerosos como sea posible y los cuales se describen de manera detallada en el capítulo "La Ruleta":

Por todo el pecho, manos - mil-. También un beso de mil bocas. Y ah, las vergas: entraban, se quedaban. "Aj, aj, aj". Abrí los ojos. Eran cuatro los hombres que me estaban tocando: el barbado, que me comía; dos más — dos chicos-, que me lamían las axilas; y el último, que me besaba la cara (estaba tan cerca que no pude distinguirlo). "Aj, aj”. De nuevo, el frasquito. Aspiré, cerré los ojos. Un ruido: metal sobre el piso. Y los hombres, mientras: "Eso, eso". Entonces, algo —algo — en la boca. Abrí los ojos y... “Aj”. Estaba chupando una verga. Los chicos no estaban ya. Cerré los ojos. “Aj, aj”. Y los gritos: "Dale, dale. Duro". Entonces, un vacío: dejé de sentir las vergas, todas mil. Abrí los ojos: el hombre de barba se había salido. Le daba paso a otro, ahora, un muchacho, que apenas entró me hizo gritar. "Te gustan gruesas, ¿verdad?", me preguntó, y de nuevo, en mi nariz, el frasquito. Aspiré, me solté -más-. Mil vergas, todas gruesas, entraban ahora: entraban, entraban... No dejaban de entrar. (Caputo 2016, cap. III, doc. 1062)

La abundancia de acciones verbales que se incluyen en este párrafo se identifica con un lenguaje de tipo neobarroco, muy vinculado con el Caribe latinoamericano (José Lezama Lima, Alejo Carpentier y Nicolás Guillén), en donde el exceso busca narrar el sinnúmero de sensaciones placenteras que disfruta el personaje.

Severo Sarduy, uno de los autores cubanos que, junto a José Lezama Lima, Alejo Carpentier y Nicolás Guillén, ha hecho uso del lenguaje neobarroco en su escritura y quien en 1972 acotó el término, sostiene que éste "refleja estructuralmente la inarmonía, la ruptura de la homogeneidad" $(1970,211)$. De acuerdo con lo establecido por Sarduy, en este lenguaje predomina lo exuberante, inestable, ambiguo y móvil, que emplea, además, figuras poéticas como la metáfora, la elipsis y la hipérbole. El lenguaje neobarroco, por otra parte, es entendido por Sarduy como un proceso de carnavalización, en la medida en que lo considera espectáculo simbólico y sincrético en que reina lo "anormal, en que se multiplican las confusiones y profanaciones, la excentricidad y la ambivalencia" $(1970,300)$.

Este lenguaje neobarroco es una transgresión del lenguaje considerado "normal" porque "se presenta como la ruptura total del nivel denotativo, directo y natural del lenguaje, como una transgresión al lenguaje somático-comunicativo, económico, austero, reducido a su funcionalidad" (Sarduy 1970, 337). Es así como las descripciones del protagonista son narradas a partir de este lenguaje neobarroco que, de acuerdo 
con Severo Sarduy es "juego, pérdida, desperdicio y placer; es decir, erotismo en tanto que actividad que es siempre puramente lúdica" (Sarduy 1972, 182). Se trata de un lenguaje que narra de forma afirmativa los encuentros sexuales que tienen los homosexuales de la novela, tanto como su voluntad por dar y recibir placer.

Pero esta característica narrativa no se limita a los momentos en que el protagonista habla de sexo. En medio de la descripción de las penurias de padre e hijo y sus planes para salir de la crisis, el autor interrumpe la historia con la narración de un hecho escabroso y trágico: una matanza a manos de grupos armados de limpieza social, quienes irrumpen en el antro nocturno frecuentado en su mayoría por miembros de la comunidad LGBT:

Pasaron noches, ocurrió la masacre.

Parecían esculturas, esos cuerpos divididos en cuartos y mitades — clavados en estacas, algunos, o empotrados en faroles, algunos, violados para siempre por un árbol一. Parecían de barro, también, y otros, de tan destrozados, parecían barro. (Caputo 2016, cap. II, doc. 488)

A raíz de este crimen, Caputo escribe al mismo tiempo sobre la homofobia, los cuerpos que cargan con el peso de ser indeseables y las violencias tanto sutiles como explícitas y desgarradoras a las que son sometidos, con las características típicas del horror perpetrado por los distintos actores armados de la guerra en Colombia y que son representadas en el recuento literario de la masacre que ocurre en la novela:

[...] estaban los ahorcados. Estos cuerpos que fueron hombres, suspendidos ahora en el aire, parecían mirar, impasibles, a los muertos de al frente. $Y$ estos muertos estaban intervenidos para parecer mujeres: les pusieron piedras en el pecho, como senos; les cercenaron la verga.

Al final, los penetrados: en ese estar sin estar, parecían esculturas, estos cuerpos insertados a una estaca. Unos, debajo, estaban en cuatro, dispuestos en círculo, como si cada uno estuviera dentro de otro. Más lejos, la rama de un árbol —el propio árbol— violaba a un cuerpo para siempre. "Sigan bailando, mariposas", habían escrito con la sangre. (Caputo 2016, cap. II, doc. 476)

En su libro Cruel Modernities (2013), Jean Franco se aproxima a la noción de crueldad contextualizada en la modernidad tardía latinoamericana. Franco revisita una serie de eventos históricos, movimientos guerrilleros y terroristas en los que se perpetraron torturas, asesinatos, masacres, violaciones sexuales y otros actos de brutalidad que han marcado para siempre el imaginario latinoamericano. En uno de los capítulos, titulado "Revolutionary Justice," Franco utiliza el término "masculinidad extrema" para referirse al colapso del núcleo fundamental que hace que los humanos reconozcan su propia vulnerabilidad y, por ende, la del otro. A partir de esta categoría, Franco revisa la violencia que se ha infringido contra aquel que es considerado un "enemigo," el cual, enfatiza la autora, no es únicamente un individuo externo sino también interno; enemigo en cuanto implica un peligro que proviene de la debilidad y el error de este $(2013,120)$. Por otro lado, Franco señala que la "masculinidad extrema" se afirma a través de la superación de atributos concebidos tradicionalmente como femeninos, tales como la ternura, y menospreciando y omitiendo todo lo que sea sinónimo de feminidad, siendo la homosexualidad su transgresión más significativa $(2013,121-23)$.

Caputo logra representar en la ficción, con lujo de detalles, la manera triste y aterradoramente célebre en la que comunidades enteras eran masacradas con sevicia por los distintos grupos armados del conflicto colombiano, y sin embargo, esta visibilidad logra generar un espíritu de resistencia en la comunidad LGBT que se narra en la historia. En la novela, es justamente la masacre narrada en la ficción la que termina creando la posibilidad de que una comunidad se muestre con mayor fuerza, que ande por la calle sin esconderse ni pretendiendo ser algo distinto. El graffiti "Sigan bailando, mariposas" escrito con sangre en el lugar de la matanza deja de ser un insulto para volverse una expresión y un nombre asumido, que ya no vulnera, sino que reivindica, como ha pasado con palabras como marica y queer.

Sin embargo, a pesar de la firma del acuerdo de paz de 2016 y los intentos de reconciliación, este sector de la población sigue sufriendo la discriminación e incluso la violencia en el llamado periodo del posacuerdo. En 2018, las organizaciones no gubernamentales Colombia Diversa y Caribe Afirmativo, que trabajan por los derechos de personas LGBT en Colombia, afirmaron que el reconocimiento legal de derechos no ha representado un impacto significativo en la disminución de violencia contra personas LGBT. En un informe reciente, estas organizaciones contabilizaron 109 muertes solamente en 2017. Por lo tanto, pese al Acuerdo de Paz, los avances en materia legal, y la reducción de homicidios en el país en los últimos años, la violencia contra lesbianas, gays, bisexuales y transgeneristas no cesa. El asunto es aun más grave en las zonas rurales o en las urbanas más marginales-como el barrio descrito por Caputo-, en donde es más visible la discriminación contra estas personas y en donde la guerra ha sido más cruenta sobre sus cuerpos porque los grupos armados y otros actores pretenden imponer su ideología y la población LGBT no encaja en su visión de la sociedad.

De esta realidad, la crueldad se presenta de manera mucho más dramática en lo que concierne al colectivo transgénero y transexual, una población en gran estado de invisibilidad y excluida y frente a la cual los avances legislativos 
relacionados con sus derechos son más bien escasos. Aunque existen aproximaciones teóricas y políticas que abordan de forma compleja la comprensión de estas orientaciones e identidades, para los efectos de este estudio, la subjetividad trans se entiende, de modo genérico, como la identificación total con el rol de género asociado al sexo opuesto, mujer en el caso del hombre y hombre en el caso de la mujer, y que conduce a la transición del cuerpo del individuo. Las personas transexuales adoptan las formas de vestir, las conductas sociales y, normalmente, las preferencias sexuales típicas del sexo opuesto; también algunos utilizan hormonas y, quienes cuentan con los recursos socioeconómicos, se someten a una operación de cambio de sexo para modificar su apariencia física. El campo literario ofrece muy contados ejemplos en donde se visibilizan, romantizan o representan estos personajes y la difícil realidad de sus condiciones de vida, como veremos a continuación.

\section{El intento de Lady masacre}

La novela Lady Masacre (2013) de Mario Mendoza se ambienta en la época de mayor popularidad de la segunda presidencia de Álvaro Uribe Vélez (2006-2010) y, en particular, se desarrolla en el mes de julio de 2008, cuando en un cinematográfico operativo, el gobierno y sus fuerzas militares lograron "el rescate de los secuestrados que tenían en su poder las FARC [y] los canales de televisión transmitían en directo la manera como descendían de los helicópteros con sus rostros radiantes y esperanzados" (Mendoza 2013, 37). Era la época en la que se empezaba por primera vez en cincuenta años a tener la percepción fomentada por el cubrimiento mediático de las acciones contrainsurgentes de que el país era más seguro gracias a la disminución de los homicidios, las masacres y los índices de ataques insurgentes.

El crimen que se retrata en la novela se inspira en la revelación de los vínculos entre los ejércitos paramilitares y buena parte de la clase política colombiana. Dichos ejércitos se agruparon bajo la poderosa organización Autodefensas Unidas de Colombia (AUC) - y experimentaron su mayor auge en la década de los noventa, adquiriendo una doble condición. Por un lado, actuar como grupos contrainsurgentes, y por otro, como grupos de protección del negocio del narcotráfico. La asociación paramilitar llegó a tener cerca de treinta mil hombres en armas y el control de una facción muy importante del territorio, en disputa abierta con la antigua guerrilla izquierdista de las Fuerzas Armadas Revolucionarias de Colombia (FARC).

Al inicio de la primera presidencia de Álvaro Uribe (20022006), se empezó a hablar de una negociación con estos grupos paramilitares que condujeran a su desarme y reinserción en la vida civil. Durante el proceso de desmovilización con las AUC, que los agrupaba, el gobierno ignoró los tentáculos que estos grupos de ultraderecha tenían en no pocos sectores políticos, económicos y entre las fuerzas militares. Estas alianzas non sanctas se habían materializado en una reunión secreta y clandestina conocida como el "Pacto de Ralito," firmado en el año 2001 entre jefes de grupos paramilitares colombianos y algunos senadores, representantes, concejales y alcaldes de diferentes regiones colombianas para crear un proyecto político que prometía, en los propios términos del documento, "refundar al país." Producto de lo anterior, en el 2002 y 2003 se empezaron a ver fenómenos políticos atípicos: regiones que contaron con un solo candidato para congreso, senado, gobernaciones y alcaldías en zonas geográficas donde los paramilitares ejercían una histórica presencia. Según las investigaciones y condenas judiciales, varios dirigentes políticos y algunos funcionarios del Estado se beneficiaron de estas alianzas por medio de la intimidación y la acción armada de los grupos paramilitares contra la población civil, con las que algunos alcanzaron cargos en alcaldías, consejos, asambleas municipales y gobernaciones, así como en el Congreso de la República y otros órganos estatales. A su vez, algunos de los políticos desviaron desde sus cargos dineros para la financiación y conformación de nuevos grupos armados ilegales y filtraron información para facilitar y beneficiar las acciones de estos grupos dentro de las que se incluyeron masacres, asesinatos selectivos y desplazamientos forzados, entre otras acciones criminales, con el objetivo de extender su poder e influencia política territorial.

Si nos remontamos a la historia reciente, podemos recordar una célebre entrevista a Carlos Castaño publicada en la revista Semana en 2005. En esta entrevista, el que fuera líder de las Autodefensas Unidas de Colombia (AUC) afirmó sin ningún viso de vergüenza que esta organización tenía de "aliados" a cerca del 35\% de los congresistas de Colombia en ese entonces. Esta afirmación desató inmediatamente una polémica a nivel nacional acerca de quiénes eran los congresistas que tenían vínculos con los grupos paramilitares. Posteriormente, con las desmovilizaciones de las AUC y tras la aprobación de la Ley de Justicia y Paz (Ley 975 de 2005), varios comandantes paramilitares denunciaron a altos funcionarios públicos de haber tenido "convenios" con estos grupos. Decenas de congresistas, alcaldes, gobernadores y diputados fueron también salpicados por el fenómeno denominado "parapolítica."

Con estos detalles históricos como telón de fondo, la trama de Lady Masacre gira alrededor de Frank Molina, anteriormente un periodista de crónica roja, quien padece de una psicosis maniacodepresiva conocida comúnmente como bipolaridad y abandona su labor periodística para convertirse en un investigador privado. ${ }^{2}$ La primera parte de la novela esboza los inicios del detective en su profesión, quien luego de aceptar casos sin mayor importancia, es contratado por doña Mariana Pombo para que se ocupe del caso de su hermano, Ignacio "Nacho" Pombo. En la novela, Pombo es uno de los congresistas involucrados en el escándalo de la 
parapolítica y miembro de la burguesía bogotana, asesinado en extrañas circunstancias y en cuyo crimen intervienen, directamente o de forma tangencial, el peso de la corrupción política representado por el escándalo de los vínculos paramilitares con altas esferas del gobierno. En esta primera parte se narra la investigación del asesinato del congresista y se hace el recuento de algunos de los principales episodios del escándalo y de algunas de las masacres paramilitares más tristemente célebres durante el proceso.

En la segunda parte de la novela, el detective se encuentra rápidamente sumido en una atmósfera de conspiraciones, amenazas y sucesos en apariencia absurdos, por lo que se le hace difícil distinguir entre los hechos de la vida real y las producciones fantásticas y extravagantes surgidas a raíz de su trastorno mental. La tercera sección de la novela tiene el mismo título de la obra y en ella se narra la historia amorosa del congresista Pombo, heterosexual y casado. Éste inicia una relación clandestina con "un transexual que se había inyectado hormonas desde su primera adolescencia y que después se mandó a operar para transformarse en lo que en realidad era, una mujer" (Mendoza 2013, 209). En esta parte culminante de la novela, Frank Molina, el detective, consigue de manera efectiva develar el verdadero crimen: la muerte del congresista no se da por un intento de robo sino producto de un crimen pasional. Y su asesina es la misma amante, Gabriela, la luchadora transexual. ${ }^{3}$

Debemos en este punto volver al contexto político de la historia, la Colombia escandalizada por el develamiento de los nexos entre políticos y paramilitarismo para controlar el Estado y crear así una concepción de patria basada en el clásico discurso nacional de tipo heteronormativo. Si retomamos las ideas acerca del discurso nacionalista en América Latina, críticas tales como Doris Sommer (1991) y Joane Nagel (2005) coinciden en afirmar que el concepto de nacionalismo y el proceso de formación de una nación se estructuran en términos y en enfoques heterosexuales, masculinos y patriarcales. El proyecto político-paramilitar para "refundar la patria" en Colombia, manifestado en el conocido Pacto de Ralito, se ajusta claramente a estos postulados nacionalistas, pero de manera radical. El proyecto nacional estaría basado en lo que Carlos Fazio denomina una "'estética' de la discriminación" a manos de la ideología paramilitar, la cual "no se trata simplemente de un proyecto armado de guerra sucia, sino de la consolidación de un modelo de sociedad" (2009)un modelo en el que no hay cabida para las ideas de izquierda, ni para todo aquello considerado contrario a los postulados de identidades nacionales afines a un concepto de sociedad de preponderancia masculina.

Con el trasfondo político de los hechos narrados en la novela de Mendoza, la aparición de la responsable de la muerte de la congresista representada en Gabriela es deliberada. El personaje de Gaby, una transexual de la más baja extracción social, representa todo lo que la ideología patriarcal y heterosexual que fundan los conceptos de una nación considera como innatural y encarna así una doble exclusión del sistema social colombiano. Por lo tanto, se convierte en una sobreviviente del extremismo que intentó imponer en su momento el modelo político paramilitar. Esta doble exclusión es proferida por las instituciones "viriles" del Estado que la consideran un miembro sin una identidad oficial femenina o masculina, y, por ende, un ser improductivo para el sistema en términos biológicos y sociales.

El romance entre Gaby e Ignacio puede interpretarse como un intento de reconciliación entre la clase dirigente y dominante colombiana y la población considerada como marginal por parte del sistema. $\mathrm{O}$ así pensaba creerlo Gaby cuando evocaba a su amante:

[...] Nacho fue conmigo muy especial. Me compraba libros, películas y revistas donde había artículos claves sobre lo que estaba pasando en el país. Luego hablábamos, comentábamos, y gracias a esas conversaciones yo iba perfeccionando mi formación. Me estaba preparando para ser su novia en sociedad, me estaba entrenando para ser su esposa [...] El cambio que estaba planeando era justamente ése: salir de los cocteles y la vida social estúpida y conectarse con ese país del cual se había alejado tanto, ese país que habían masacrado en su finca, ese país que estaba representado en los fanáticos cuando yo me subía al ring en la Arena Bogotá [...]" (Mendoza 2013, 241).

Sin embargo, el intento se convierte en una nueva traición al darse cuenta el congresista de la imposibilidad de lograr cambiar ese mismo sistema establecido pues, en palabras de Gaby,

[...] la fuerza de su clase social, esas leyes estrictas que obligan a individuos como él a cerrar filas cuando se sienten descarriados, terminaron imponiéndose [...] él se empecinó en continuar su carrera política, estaba a punto de empezar a cobrar todos los favores que le había hecho a los paramilitares. Tenía planes de llegar a ser presidente del Congreso y, en unos años, lanzarse incluso a la Presidencia de la República. Y claro, un hombre que piensa en el máximo cargo de su país no se puede alinear con una mujer como yo $[\ldots](242)$.

Es entonces cuando Gaby, durante la última noche que pasa con el congresista, decide vengarse y de paso vengar a toda esa población:

[...] y sentí que en mi mano estaba el desquite, la venganza, que yo era la única que podía cobrar ahora la cuenta que esa clase alta arrogante, mentirosa y tramposa tenía con nosotros, con los de abajo, con los que para ellos sólo somos carne de cañón [...] y en un acto, primero de fuerza, de aguante, 
en segundo lugar de venganza grupal [...] levanté la navaja y la dejé caer una y otra vez sobre ese cuerpo tan amado, tan querido, tan mío [...] (246).

A través del acto de venganza de este personaje subalternizado, la novela rehúsa apostar por una lectura de desagravio nacional con las víctimas de los paramilitares y su unión con los políticos en Colombia, resaltando, en cambio, la incapacidad de la clase dirigente colombiana de intentar construir o plantear esfuerzos más liberales por construir la nación del posconflicto. Esta venganza nos puede sugerir también que Gaby logra vengar su propia exclusión social y sexual del sistema y la de su pueblo con la muerte de tres figuras masculinas: su propia masculinidad (al convertirse en transexual), la figura del congresista (el poder nacional), e Ignacio Pombo, miembro de la oligarquía bogotana (el poder hegemónico).

Sin embargo, la "venganza" de un sujeto transexual que elimina los tres símbolos hegemónicos de masculinidad es en vano por cuanto no logra resarcir a las clases sociales que pretendía vengar y ni siquiera logra realizarse ella como una mujer independiente, miembro de la élite con la cual esperaba reconciliarse. Es el final de una transexual que termina viviendo en las mismas condiciones de pobreza y exclusión social, agravadas esta vez por no poder volver al ring de lucha libre y tiene que regresar a su barrio marginal para vivir oculta en casa de su madre. Su historia no logra ningún cambio de mentalidad en los demás personajes implicados en esta historia.

La novela termina con un caso exitoso para el detective Molina, quien, como sabemos, logra descubrir a la autora del crimen del congresista, pero, en un acto de complicidad con Gaby, decide reportar lo sucedido con su jefa Mariana Pombo, la hermana del congresista, diciéndole que la joven transexual "estaba muy enferma, que tenía cáncer terminal y que estaba agonizando en la casa de su madre, en una casa miserable al sur de la ciudad" (249). Ante ello, Mariana prefiere a toda costa cerrar el caso de inmediato pidiéndole al detective "que se olvide todo... [...]" (249). La reacción de Mariana confirma así la postura que incubó en su momento el conflicto colombiano al olvidarse y mantener oculto a ese país marginal habitado por los excluidos del sistema, aquellos condenados a vivir en el infierno representado en esta obra literaria.

La novela de Mendoza tiene ciertas características enmarcadas en un contexto urbano y una violencia gráfica en primer plano; sin embargo, existen otro tipo de representaciones que muestra la problemática que afrontan las disidencias sexuales pero desde las comunidades rurales, con una violencia más contenida. Esto lo vemos a reglón seguido con el caso de María Luisa Santos - una campesina transexual del Departamento de Boyacá en los andes Orientales colombianos.

\section{La señorita María}

En Colombia, la Constitución de 1991 reconoce el derecho a la identidad, la libertad de la sexualidad y la libertad de determinar el propio género. Un decreto ministerial del 4 de junio de 2015 facilita a las personas transgénero, intersexuales y transexuales determinar o corregir su género en su cédula o tarjeta de identificación mediante un procedimiento notarial simple y evitar los exámenes psicológicos y médicos para determinar dicho cambio. Los recién nacidos y niños intersexuales tienen acceso a asistencia médica integral sin el requisito previo de tener una tarjeta de identificación. El matrimonio y las uniones libres del mismo sexo, así como las adopciones por padres del mismo sexo, son reconocidos por el Estado, mientras que la discriminación por género y orientación sexual es un delito castigado por la ley en Colombia.

Pero en la zona rural, la señorita que comenzó a llamarse "María" a los 18 años en reverencia a la Virgen María, dice haber sido rechazada por su comunidad debido a que prefiere usar vestidos y calzar tacones a la iglesia, pues en sus palabras, "la Beata María nunca usó pantalones." Durante seis años, Rubén Mendoza (La sociedad del semáforo, 2010 y Tierra en la lengua, 2014) ha logrado plasmar en su documental la vida de María Luisa Fuentes o la Señorita María, una agricultora que vive sola en una cabaña remota, rodeada de campos de maíz, eucaliptos y campos verdes. Es la historia de un ser humano que se siente mujer y vive como mujer, una campesina transexual del pueblo de Boavita en Boyacá, al nororiente de Colombia.

María es conocida por algunos en el pueblo por su capacidad de trabajo en el campo recolectando maíz, o por su fuerza para transportar cantinas de leche al mercado. También le admiran su devoción religiosa como cualquier otro miembro de un pueblo con fuerte arraigo conservador y católico. Sin embargo, la mayoría no cuenta con una opinión benévola. De manera curiosa, Boavita es uno de los pueblos en donde surgieron los chulavitas, los escuadrones de la muerte del partido conservador durante la Violencia, el período del violento conflicto político entre conservadores y liberales entre 1946 y 1958. En esta región, aun muchos de los ancianos recalcitrantes se encargan de recordar el pasado de la mujer cuando era un niño en la escuela del pueblo. Para ellos, la Señorita María sigue siendo un fenómeno de la naturale$\mathrm{za}$, nacida fuera del matrimonio, producto del incesto. Para otros, ella ni siquiera existe en este mundo, "[...] era mejor no hablar con nadie," afirma en su testimonio. La discriminación y la falta de comprensión llevaron incluso a algunos pobladores a contactar al sacerdote local para "exorcizar al demonio en mí."

No obstante, María logró sobrevivir no solo a la intolerancia de su comunidad, sino también a la violencia que devastó gran parte del campo, especialmente en ese rincón 
remoto de Colombia, un pueblo con una tradición conservadora y violenta $\mathrm{y}$, hasta hace poco, con una fuerte presencia guerrillera.

Cuando se filma el documental, María Luisa tiene 45 años y hace un recuento de las distintas etapas de su vida marcada por secretos familiares y prejuicios sociales que la han discriminado, aislado y culpado por un crimen del cual no es más que víctima inocente. Su madre, María Patrocinio Burgos, que según se enteró después era su abuela, la sacó de la escuela por los ataques epilépticos que sufría y los profesores no supieron diagnosticar. La consideraron poseída por el demonio y se quedó sin educación, encargándose de labores domésticas y del campo, aislada de todo tipo de contacto social. Para empeorar el cuadro, María Luisa es hija de una pareja de hermanos, habiendo sido concebida en Bogotá y traída al pueblo de regreso por su madre biológica, quien la dejó con su abuela y se fue sin volver nunca más. La abuela la habría criado con recelo de que se expusiera al público y mantenido alejada de muchas personas por mucho tiempo.

La puesta en escena del testimonio, en el que María narra la historia de sus padres biológicos y el episodio del incesto, es lo que genera más debate entre algunos académicos. El antropólogo Diego Vallejo Díaz en su columna "La película de Rubén Mendoza no le hace justicia a la vida de María Luisa," sostiene que las preguntas del director tienen como fin mostrar la incomodidad de María al hablar del tema:

[El director] arrincona a María, frente a la cámara por supuesto, para llevarla al punto de quiebre en que termina llorando desolada y sus palabras de dolor siguen sonando mientras la cámara toma un paisaje de las montañas. ¡Cuánta audiencia atraerá esta imagen! ¡Qué uso tan conveniente del dolor (despertado por el mismo arrinconamiento del productor) para esta "hermosa" escena! (Vallejo Díaz, 2017).

Sin embargo, Vallejo Díaz tiene una visión parcial de lo que quiere hacer la película. El diálogo y su puesta en escena es justamente la oportunidad que tiene la protagonista para lograr una visibilidad total, no sólo de forma física sino también de manera íntima, al desanudar su pasado frente a la cámara y hacer una catarsis que estremece. De hecho, el tema que realmente causa estupor es justamente el de la discriminación permanente y constante por parte del Estado, de la sociedad que se escandaliza por la relación incestuosa de sus padres y de los vecinos de su propia comunidad. Aunque María se presenta ante todos con un nombre y una apariencia de mujer, las personas la llaman torpemente en masculino, mezclan los artículos, confunden su género, la violentan al no reconocerla como es. "Él es muy bueno; ella vive por allá; a María la conozco desde que era un pequeño," suelen decir. $Y$ aunque muchos nos referimos a ella como una campesina transexual, cuando se le pregunta al respecto dice "que no sabía qué significaba esa palabra. Ella no se detiene a dar explicaciones de por qué ella sí es una mujer. Ella no va por ahí excusándose con todo el mundo por ser lo que es: ella es una mujer y punto" (González Gil, 2017).

El cuerpo intervenido es un logro que materializa la historia de lucha de las mujeres como María en contra de un sistema de género que les ha impuesto la masculinidad de forma compulsiva y, en este documental, la señorita María demuestra de forma contundente que ser mujer es el producto de su persistencia y de la capacidad de decisión y agencia sobre su propio destino, ejemplificando lo expuesto por la crítica norteamericana Judith Butler en su estudio sobre el género y la identidad. Ella afirma que las prácticas transgénero tienen el potencial de impactar en la vida política debido a que ponen en duda quién o quiénes cuentan como personas, tanto como las normas que gobiernan aquello que debe ser considerado como tal: "the very notion of 'the person' is called into question by the cultural emergence of those 'incoherent' or 'discontinuous' gendered beings who appear to be persons but who fail to conform to the gendered norms of cultural intelligibility by which persons are defined" (Butler 1990, 23).

Para concluir y con la intención también de dejar abierto el diálogo, considero que este tema en los momentos actuales en los que se habla de la necesidad de lograr un ambiente de paz y reconciliación nacional debe(ría) ser más relevante. Bien es cierto que para académicos como Eduardo Caro Meléndez, la presencia de lo queer en Colombia no ha sido un fenómeno reciente y han sido "muchos los autores y críticos colombianos que han orientado su enfoque hacia la producción, estudio y análisis de las culturas gays, lesbianas, bisexuales y transgéneros" en el campo literario, fílmico, teatral y performativo. Hoy en día y a pesar de los impedimentos partidistas e ideológicos de los últimos años, son latentes los esfuerzos oficiales y no gubernamentales (Colombia Diversa, el Centro Nacional de memoria Histórica, la Jurisdicción Especial para la Paz, la Comisión de la Verdad, entre otras instituciones) de incluir los testimonios y casos de las víctimas del conflicto colombiano que hacen parte de la comunidad LGBT. ${ }^{4}$

Como sabemos después de décadas de guerra interna, Colombia está tratando de construir la paz entre civiles y exguerrilleros provenientes de las FARC. Según un informe publicado en 2018 por la plataforma de noticias Marketplace, desde el 2017 el gobierno colombiano ha pagado aproximadamente tres millones de dólares como reparaciones a 730.000 víctimas y se calculaba que aproximadamente ocho millones de personas se han registrado como víctimas. Pero los activistas dicen que se está pasando por alto a un grupo: los miembros de la comunidad LGBT. De las más de ocho millones de víctimas del conflicto armado, existe un pequeño registro de lesbianas, gays, bisexuales y transexuales que se han visto afectados por la guerra. De acuerdo con las cifras de la Unidad de Víctimas, se trata de 2.201 personas hasta abril de 2017. Según el activista LGBT Alejandro Lanz, "muchas 
personas prefieren y optan por no registrarse como LGBT ante el estado por temor a no ser reconocidas como víctimas" (Barrett, 2018) y explican que la gente teme que el gobierno los discrimine si se identifican como LGBT. De ahí la necesidad urgente de ir más allá de estas versiones oficiales para denunciar, registrar y visibilizar las complejas realidades de la comunidad LGBT que ha sido víctima del conflicto armado colombiano. Esto se puede lograr por medio de la promoción y de brindarle agencia a aquellos proyectos artísticos que se dedican al trabajo con mujeres, personas queer y trans. La visibilización de estos seres humanos no es solo un acto de valentía, sino también un acto de resistencia.
Gracias a la difusión de más y diversas formas de expresión que busquen ser lo más inclusivas posibles desde el punto de vista de la identidad sexual o de género con historias reales (la vida de María Luisa Santos, en el documental de Rubén Mendoza), con la difusión de historias inspiradas en la realidad (las narraciones de Mario Mendoza y Giuseppe Caputo), se logrará dar visibilidad social a los miembros de una comunidad que no ha dejado de ser víctima de todas las violencias y que, sin embargo, en más y más casos, quiere ser visible al tiempo que resistir en el intento.

\section{Obras Citadas}

Ángel, Albalucía. 1982. Misía señora. Barcelona: Editorial Argos Vergara.

Barrett, Sarah. 2018. “Colombia's LGBT community may not be benefiting fully from reparations system”. Marketplace. Disponible en: https://www.marketplace.org/2018/02/26/colombias-lgbt-community-may-not-be-benefiting-fullyreparations-system/, febrero 26,2018

Butler, Judith. 1990. Gender Trouble. Feminism and the Subversion of Identity. New York: Routledge.

Butler, Judidth. 1993. Bodies That Matter: On the Discursive Limits of "Sex". New York: Routledge.

Caputo, Giuseppe. 2016. Un mundo huérfano. Bogotá: Penguin Random House Grupo Editorial.

CNMH. 2014. Areas de trabajo. Acciones en el territorio. Disponible en http://www.centrodememoriahistorica.gov.co/areastrabajo, enero 31, 2014.

CNMH. 2015. Aniquilar la diferencia: lesbianas, gays, bisexuales y transgeneristas en el marco del conflicto armado colombiano. Bogotá: Centro Nacional e Memoria Histórica.

CNMH. 2018. Un carnaval de resistencia: Memorias del reinado trans del río Tuluní. Bogotá: Centro Nacional e Memoria Histórica.

CNMH. 2019. Ser marica en medio del conflicto armado. Memorias de sectores LGTB en el Magdalena Medio. Bogotá: Centro Nacional de Memoria Histórica.

Caro Meléndez, Eduardo. 2017. "Hacia una queerización de la producción cultural colombiana. Literatura colombiana queer". Revista de Estudios Colombianos No. 49.

Fazio, Carlso. 2009. "Paramilitarismo”. Editorial. La Jornada. Disponible en: www.jornada.unam.mx/2009/09/21/ politica/020a1pol, 2009.

Franco, Jean. 2013. Cruel Modernity. Durham and London: Duke University Press.

González Gil, Matilda. 2017. "He sacado la cara de dentro de la ruana”, señorita María. El Espectador. Disponible en www. elespectador.com/cromos/vida-social/he-sacado-la-cara-de-adentro-de-la-ruana-senorita-maria-25874, noviembre 19, 2017.

Ley 975 de 2005 o Ley de Justicia y Paz. Diario oficial 45.980. Congreso de Colombia. Bogotá, julio 25, 2005.

Mendoza, Mario. 2013. Lady Masacre. Bogotá: Planeta Colombiana. 
Nagel, Joane. 2005. "Nations". En: M. Kimmel, J. Hearn, R.W. Connell (eds.). Handbook of Studies on Men and Masculinity (pp. 397-413). Thousand Oaks, London, New Delhi: Sage.

Proimágenes. 2017. Poster oficial del documental Señorita María, la falda de la montaña. Rubén Mendoza.

Sánchez Baute, Alonso. 2004. Al Diablo la maldita primavera. Madrid: Alfaguara.

Sarduy, Severo. 1970. "Conversación con Severo Sarduy”. Entrevista de Emir Rodríguez Monegal. Revista de Occidente. Separata. No 93: 315-343. Disponible en: http://anaforas.fic.edu.uy/jspui/handle/123456789/38334 diciembre, 1970.

---. 1972. "El barroco y el neobarroco”. En: C. Fernández Moreno (coord. e intr.) América Latina en su literatura (pp. 167-184). México: Siglo XXI.

Sedgwick, E. K. 1993. Tendencies. Durham and London: Duke University Press.

Señorita María, la falda de la montaña. 2017. Dir. Rubén Mendoza. Colombia: Caracol Televisión. Dago García Producciones, DiaFragma, Ministerio de Cultura de Colombia, Proimágenes Colombia.

Sommer, Doris. 1991. Foundational Fictions: The National Romances of Latin America. Berkeley: University of California Press.

Vallejo, Fernando. 1994. La virgen de los sicarios. México: Alfaguara

Vallejo Díaz, Diego, 2017. "La película de Rubén Mendoza no le hace justicia a la vida de María Luisa”. El Tiempo. Disponible en: http://blogs.eltiempo.com/bloguero-invitado/2017/12/19/la-pelicula-ruben-mendoza-no-le-justicia-la-vida-maria-luisa/ diciembre 19, 2017

Viteri, María Amelia, Serrano, José Fernando y Vidal-Ortiz, Salvador. 2011. “Cómo se piensa lo "queer” en América Latina?” Presentación del Dossier Íconos. Revista de Ciencias Sociales (39): 47-60.

\section{Notas}

1. Aunque existe una serie de ampliaciones de la sigla con el fin de incluir a otras comunidades, como a las personas intersexuales (LGBTI), queer (LGBTQ), y asexuales (LGBTA), dando origen a siglas como LGBTQI, entre otras, en este ensayo utilizaré la sigla LGBT compuesta por las iniciales de las palabras 'lesbianas,' 'gays,' 'bisexuales,' y 'transgeneristas,' por ser la utilizada de manera global por Colombia Diversa, la organización de defensa de derechos humanos de las personas LGBT líder en Colombia.

2. La psicosis maniacodepresiva es un trastorno biomédico, caracterizado por episodios alternos de euforia excesiva (llamada fase maníaca) y de depresión. La manía se manifiesta con síntomas graves de excitabilidad, habla alterada y efusiva, expresión emocional intensa, conductas irresponsables y peligrosas, grandes gastos de dinero, conductas de riesgo, sexuales o de otra índole, etc. Los comportamientos de estas personas durante una fase maníaca suelen ser muy llamativos y graves. En la fase depresiva, suelen tener los síntomas de una depresión grave, pudiendo haber ideación suicida.

3. La lucha libre se inspira en el deporte olímpico conocido como Lucha Grecorromana o Lucha Libre Olímpica, en el cual cada participante intenta derribar a su contrincante mediante el uso de llaves y técnicas de forcejeo, hasta hacerlo caer y mantenerlo sobre la lona por un tiempo que determina el juez. El deporte se ha convertido en una atracción de masas, como el boxeo, siendo muy popular la variante femenina de esta modalidad. En la novela, sin embargo, la competencia es un espectáculo distante del evento deportivo en el cual se inspira. Pensemos en países como México donde existe todo un culto alrededor de muchos de sus participantes masculinos. Si bien se han documentado casos de participantes que son transgénero, estos no son comunes y mucho menos lo son en la lucha libre de espectáculo.

4. Al regirnos a las estadísticas, en el informe Aniquilar la diferencia (2015), el Centro Nacional de Memoria Histórica reportó 1795 personas LGBT como víctimas del conflicto armado. De igual forma, estableció que el 89\% fue víctima de desplaza- 
miento forzado, el 20\% recibió amenazas de muerte, el $7 \%$ fue víctima de asesinato selectivo, y el 4\% sufrió algún tipo de violencia sexual. 